\title{
Spontaneous Rupture of Incisional Hernia - A Case Report
}

\author{
Maulana Mohammed Ansari*1, Shahla Haleem² ${ }^{2}$, Mohd Sadik Akhtar ${ }^{1}$, Wasif Mohd Ali ${ }^{1}$ and Syed Hasan Harris ${ }^{1}$ \\ ${ }^{1}$ Department of Surgery, Aligarh Muslim University, India \\ ${ }^{2}$ Department of Anaesthesiology, Aligarh Muslim University, India \\ Submission: April 22, 2017; Published: May 03, 2017 \\ *Corresponding author: Maulana Mohammed Ansari, Ex-Professor of Surgery, Department of Surgery, Aligarh Muslim University, B-27, Silver Oak \\ Avenue, Street No. 4, Dhaurra Mafi, Aligarh, UP, India, Tel: 0571-2720044; 0091-9557449212; Email: mma_amu@yahoo.com
}

\author{
Abstract \\ A 40- year old female presented with spontaneous rupture of 8-year old Incisional hernia through midline abdominal scar and evisceration \\ of small bowel. Emergency operation with polypropylene mesh hernioplasty was carried out. Outcome with a brief review of literature is \\ discussed.
}

Keywords: Spontaneous rupture; Incisional hernia; Ruptured hernia; Ruptured incisional hernia; Emergency mesh repair

\section{Introduction}

Incidence of postoperative incisional hernia has been at least $10 \%$ on long-term follow-up even in the best centers [1]. The hernia steadily increases in size with attendant heavy sickening/ dragging sensation aggravated by coughing/ straining and recurrent attacks of incomplete obstruction with colicky pain \& vomiting; sometimes complicated by complete obstruction and strangulation, and often intertrigo in deep creases between large dependant hernia and abdominal wall. Late dehiscence of incisional hernia is rare [2]. A case of spontaneous rupture of incisional hernia with bowel evisceration is presented here with a brief review of literature.

\section{Case Report}

A 40-year old female presented with the complaint of bowel protrusion from a ruptured ventral incisional hernia. The hernia had been present for last 8 years through the lower part of the midline scar, with history of emergency laparotomy for tubercular ileal perforation before 10 years through midline incision, \& elective open cholecystectomy before 12 years through subcostal incision. On examination, patient was pale, pulse rate 106/min. and B.P. 206/158 mmHg. Subcostal scar on abdomen was intact while a large incisional hernia was present through the lower part of the midline scar that was thin and papery with rupture at the bottom of the hernia sac through which a loop of pink viable small bowel was eviscerating (Figure 1).

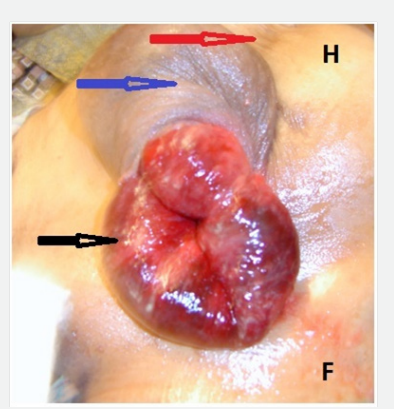

Figure 1: Photograph showing ruptured incisional hernia with evisceration of bowel. $\mathrm{H}$, Head end of the patient; F, Foot end of the patient; Red arrow, indicates the upper part of the previous laparotomy scar; Blue arrow, indicates the incisional hernia; Black arrow, indicates the bowel eviscerating through a rupture in the hernial sac of incisional hernia

The bowel was reduced by gentle digital manipulation after cleansing with warm saline (Figure 2) and urgent operation was planned. Her haemogram, renal function and blood sugar were within normal limits, and ABG (Acid base and gas) analysis showed mild respiratory alkalosis. Nitroglycerine intravenous infusion@ @ $4 \mu \mathrm{g} / \mathrm{Kg} /$ minute was started to reduce the blood pressure. Emergency operation was performed after normalization of the blood pressure. A loop of small bowel was found adherent to superior aspect of the hernial defect and it was dissected free; hernial sac with redundant skin was excised, and the large hernial defect of about $10 \times 8 \mathrm{cms}$ in size was 
closed by polypropylene mesh underlay repair with placement of omentum between the mesh and bowel loops. Postoperative period was uneventful except for a minor stitch abscess at the lower end of the wound that cleared in 3 days and patient was discharged from the hospital on 8th day. Patient was followed up regularly in the outpatient department. At 2-year follow-up, the scar was healthy and intact with no recurrence of hernia.

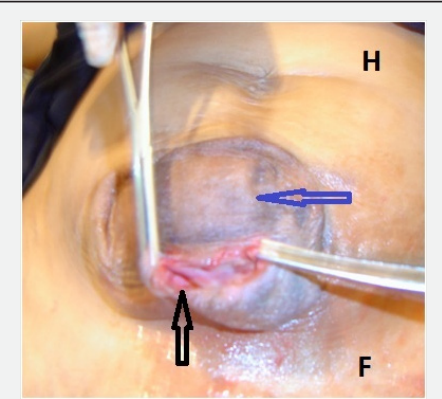

Figure 2: Photograph showing ruptured incisional hernia after reduction of eviscerated bowel. $\mathrm{H}$, Head end of the patient; $F$, Foot end of the patient; Blue arrow, indicates hernial sac of the incisional hernia; Black arrow, indicates the rent/rupture in the hernial sac of incisional hernia.

\section{Discussion}

With time, incisional hernia becomes large \& dependant. The overlying skin gets thinned out and avascular with resultant atrophy; areas of ischaemic necrosis appear with constant risk of ulceration \& infection. This may rarely progress to dehiscence of the attenuated coverings of the hernia spontaneously or due to increased intra-abdominal pressure [2]. When eviscerated bowel is easily reducible into the abdomen and no gross infection is present, emergency repair is recommended preferably using mesh $[3,4]$, and this policy was adopted in our patient with good results. However, in presence of unfavorable conditions of strangulation, local infection, obesity and cardio-pulmonary problem, the primary hernioplasty is considered hazardous, and the two-stage procedure of emergency simple skin closure after excision of redundant atrophic skin followed by elective hernioplasty later on is preferable [5].

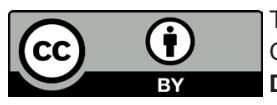

This work is licensed under Creative Commons Attribution 4.0 Licens DOI: 10.19080/OAJS.2017.04.555626
Our experience and review of the literature indicate that late dehiscence may rarely develop in long-standing neglected incisional hernia [6,7], and hence formal hernioplasty is strongly recommended once post-operative incisional hernia is detected. In order to safeguard against this potentially fatal but preventable complication, all patients with incisional hernia should be encouraged and convinced for need of early elective operation, especially in developing countries with limited resources, ignorance and illiteracy, often coupled with lack of timely access to surgical care.

\section{Conclusion}

Long standing incisional hernia has a small but definite risk of late spontaneous rupture. In absence of unfavorable conditions, emergency repair using polypropylene mesh is easily accomplished with satisfactory results. Patient education and persuasion for early elective hernioplasty is crucial to safeguard against this potentially fatal but preventable complication.

\section{References}

1. Abrahamson J. Hernias (2001) Post-operative ventral abdominal hernia. In: Zinner MJ, Schwartz SI, Ellis H (eds.), Maingot's Abdominal Operations 1: 548-568.

2. Agarwal PK (1986) Spontaneous rupture of incisional hernia. Br J Clin Pract 140: 443-444.

3. Hartley RC (1962) Spontaneous rupture of incisional hernia. Br J Surg 49: 617-618.

4. Senapati A (1982) Spontaneous dehiscence of an incisional hernia. Br J Surg 69: 313-314.

5. Hamilton RW (1966) Spontaneous rupture of an incisional hernia Br J Surg 53(5): 477-479.

6. von Helvig H (1958) Uber songenannte spontanrupturan von hernien. Schweiz Med Wschr 88: 662-666.

7. Ogundiran TO, Ayantunde AA, Akute 00 (2001) Spontaneous rupture of incisional hernia- a case report. West-Afr J Med 20(2): 176-178.

Your next submission with Juniper Publishers will reach you the below assets

- Quality Editorial service

- Swift Peer Review

- Reprints availability

- E-prints Service

- Manuscript Podcast for convenient understanding

- Global attainment for your research

- Manuscript accessibility in different formats ( Pdf, E-pub, Full Text, Audio)

- Unceasing customer service

Track the below URL for one-step submission https://juniperpublishers.com/online-submission.php 